\title{
CONTROL IN $W_{2}^{(1)}$ OF NONLINEAR INTERCONNECTED SYSTEMS OF NEUTRAL TYPE
}

\author{
E. N. CHUKWU ${ }^{1}$
}

(Received 22 October 1992; revised 5 May 1993)

\begin{abstract}
In this paper we resolve the problem of controllability of nonlinear interconnected systems of neutral type. We consider two types of systems, a general one, and one in which some control appears linearly. In each case we insist that each isolated system of the interconnected problem is controlled by its own variables while taking into account the interacting effects. Controllability is proved by assuming some controllability criteria of each isolated system and some growth condition of the interconnecting function. Fixed point and open mapping theorems are used. Examples from economics and engineering are presented.
\end{abstract}

\section{Introduction}

It has long been recognized that the flip-flop circuit in Figure 1, which is the basic element in a digital computer, can operate as a memory device. The crucial assumption needed is that the single equilibrium $\left(v^{*}, i^{*}\right)$ of the dynamics of the system be globally asymptotically stable. See Slemrod [33] for the insight and Hale [22, page 5] for the conversion of the partial differential equation satisfied by the current, $i$, and voltage, $v$, into an isolated functional differential equation of neutral type. In a recent paper [11], the time optimal control problem of these equations was posed and investigated as a natural extension of the stability theory. The focu $s$ was on the isolated single circuit in Figure 2. But this is not all the problem is about. In a computer system, the single circuit is interconnected with others in a well-defined but complicated fashion, yielding an interconnected composite system represented diagrammatically in Figure 3.

Uniform asymptotic stability of interconnected systems of neutral type was explored in [9]. In this paper we initiate our studies of the controllability in function space of interconnected nonlinear systems of neutral type. Guided by the basic insight of Michel and Miller [28] we analyze large scale systems in terms of their subsystems

\footnotetext{
'North Carolina State University, Department of Mathematics, Raleigh, NC 27695-8205, U.S.A.

(C) Australian Mathematical Society, 1994, Serial-fee code 0334-2700/94
} 


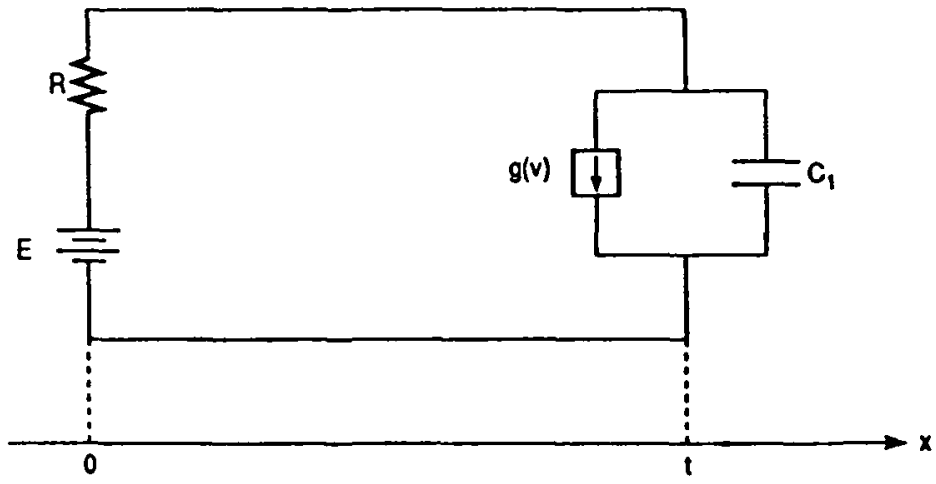

FIGURE 1.

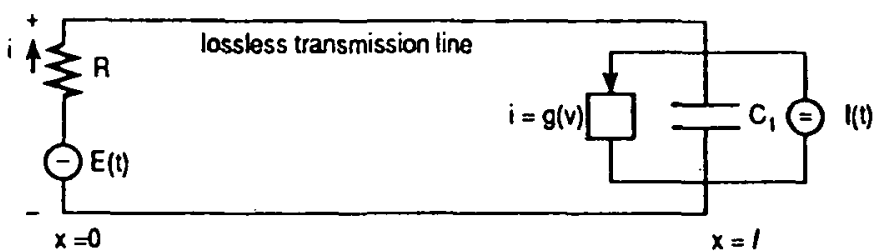

FIGURE 2.

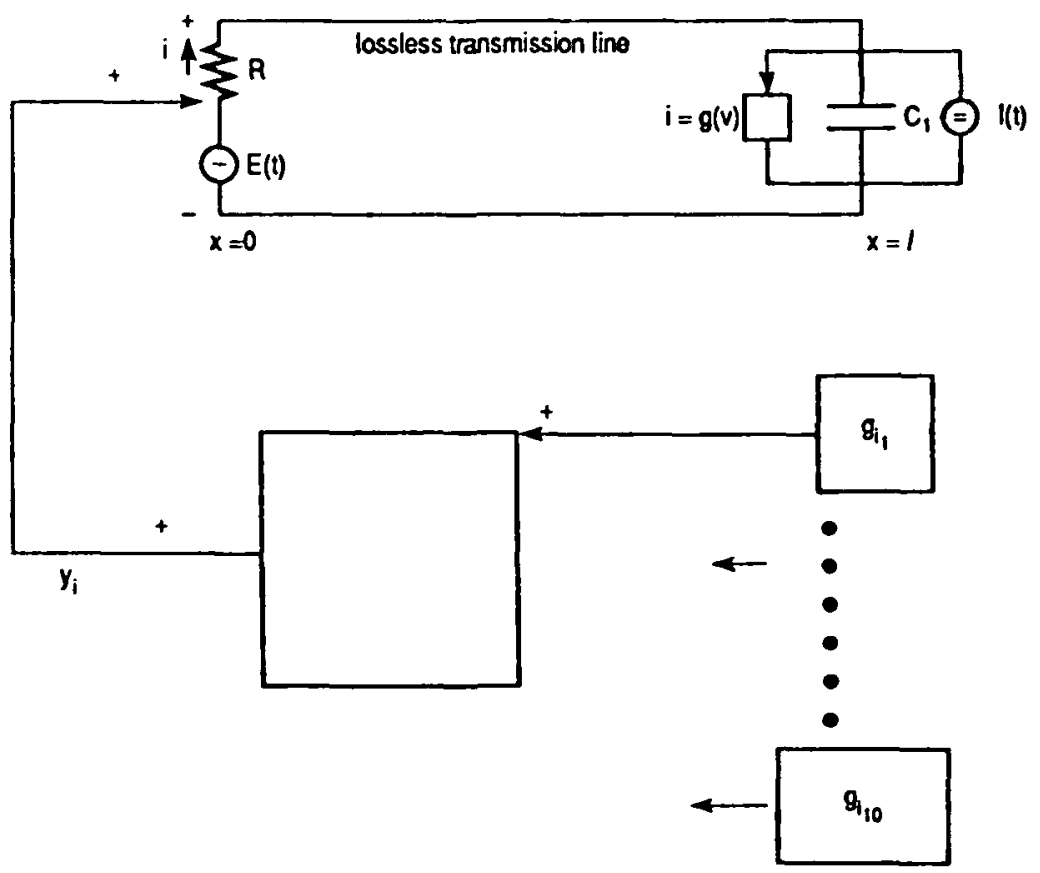

FIGURE 3. 
and the growth properties of their interconnection. Function space controllability of the overall interconnected system will be proved if we assume that the subsystems are controllable with a nice interconnection structure.

We insist that each subsystem is controlled by its own variables while taking into account the effects of interconnections. Thus our point of view is that the interacting effects are measured locally in the $i$ th subsystem as an expression of the effects of other subsystems on the $i$ th subsystem. First, conditions are stated for the controllability of the free isolated nonlinear subsystem. Assuming controllability for the free subsystem and a certain growth condition for the interaction function, we prove the controllability of the overall interconnected system.

It may reasonably be asked whether controllability questions of systems of neutral type are worth the effort to investigate them. The author believes that optimal control of such systems is the central global issue of the future: such dynamical systems may well describe the growth of national economies, whose control determines the issue of war and peace for the remainder of this century and the next. Indeed, Kalecki [24] and [1] argued that the growth of capital stock $x(t)$ of a single firm is given by

$$
\dot{x}(t)=I(t)=a_{0} x(t)+a_{1} x(t-h),
$$

where $a_{i}$ are constants and the delay $h$ represents the time lag between the decision to invest and the deliveries of capital equipments. The crucial assumption for (1.1) is that the net capital formation $\dot{x}(t)$ is given by $I(t)$. To obtain $(1.1)$, Kalecki assumes that the decision to invest $B$ is given by

$$
B(t)=a(1-c) y(t)-k x(t)+\epsilon,
$$

$a, c, k$ are constants. $\epsilon$ may be time varying. $y$ is income (output). $x(t)$ denotes the stock capital assets at time $t$. Later as an exercise [1, 8.4, no. 3, page 254], Kalecki suggests that the decision to invest should be

$$
B(t)=a(1-c) y(t)-k x(t)+\epsilon+v \frac{d y}{d t} .
$$

The outcome of this analysis is the functional differential equation of neutral type

$$
\frac{d}{d t}\left(x(t)-a_{-1} x(t-h)\right)=a_{0} x(t)-a_{1} x(t-h)+a_{2} .
$$

This is a functional differential equation of neutral type which describes the growth of capital stock of a single firm. We can introduce $b(t) u(t)$ at the right hand side of this system to obtain

$$
\dot{x}(t)+a_{-1} \dot{x}(t-h)=a_{0} x(t)+a_{1} x(t-h)+b(t) u(t) .
$$


We interpret $b(t) u(t)$ as follows. If $0 \leq u(t) \leq 1$, then $u(t)$ is the fraction of "available capital assets, $b(t)$ " at time $t$ that is allocated to investment. If $-1 \leq u(t) \leq 0$ then $u(t)$ is the fraction allocated to consumption or for payment of taxes. Thus $-1 \leq u(t) \leq 1$ and $u(t)$ is an investment consumption strategy which is appropriated as a control to drive an initial capital endowment $\phi$ to a target while minimizing a cost function.

To motivate a nonlinear system of the form (1.3) which is interconnected by the so-called "solidarity" function, we argue as follows. Let $Z$ denote aggregate demand consisting of consumption $(C)$, investment $(I)$, net exports $(X)$ and government outlay $(G)$. These differentiable functions are related as follows:

$$
Z=C+I+X+G
$$

where

$$
C=C_{0}+c(y-T), \quad 0<c<1,
$$

and $y-T$ is the current after-tax income;

$$
T=T_{0}+f_{1}(y)
$$

$T_{0}>0$ is the level of non-income taxes, and $f_{1}(y)$ is the income taxes.

$$
X=X_{0}-f_{2}(y)-e R, \quad 0<m<1, \quad e_{1}>0,
$$

where $f_{2}(y)$ is the part of income that is spent on other countries' products, $X_{0}$ is autonomous net exports, and $R$ is the real rate of interest.

$$
G=f_{3}(y(t-h))+v(t)
$$

where $f_{3}$ is public consumption which is dependent on the previous high income, and $v(t)$ public investment:

$$
I(t)=I_{0}(t)+g(\dot{y}(t-h)) .
$$

Thus

$$
\begin{aligned}
Z(t)=\left(Z_{0}(t)+f_{3}(y(t-h))+v(t)+c y(t)-c T_{0}(t)\right. \\
\\
\left.-c f_{1}(y)+g(\dot{y}(t-h))-f_{2}(y)\right)-e_{1} R,
\end{aligned}
$$

where $Z_{0}(t)=I_{0}+X_{0}+C_{0}$. From the model equations of money demand and supply [27], we deduce that

$$
R=\frac{k y}{r}-\frac{1}{r}\left(\frac{M_{0}}{P_{0}}-j\right)
$$


since

$$
\begin{aligned}
L / P & =M / P, \\
L / P & =j+h y-r R, \\
M & =M_{0}, \\
P_{i} & =P_{0} .
\end{aligned}
$$

Hence $M$ is the nominal value of money supply which is controlled by the Central Bank, $P$ is the prize level. The real demand for money is denoted by $L / P$. The symbol $j$ is autonomous real money demand. With this $R$ we deduce that

$$
\begin{aligned}
Z(t)= & Z_{0}(t)+y(t)\left(c-\frac{e_{1} k}{k}\right)+f_{3}(y(t-h))-\left(c f_{1}(y(t))+f_{2}(y(t))\right) \\
& +\frac{e_{1}}{r}\left(\frac{M_{0}}{P_{0}}-j\right)-c T_{0}(t)+g(\dot{y}(t-h))+v(t) .
\end{aligned}
$$

Following Allen [1] we postulate that $d y(t) / d t=-\lambda(y(t)-Z(t))$, where $\lambda$ is a constant. Thus

$$
\begin{aligned}
\dot{y}(t)-\lambda g(\dot{y}(t-h))= & -\lambda\left(1+\frac{e_{1} k}{r}-c\right) y(t)-\lambda\left(c f_{1}(y(t))+f_{2}(y(t))\right) \\
& +\lambda f_{3}(y(t-h))+\frac{e_{1} \lambda}{r}\left[\frac{M_{0}}{P_{0}}-j\right]+\lambda v(t)+\lambda Z_{0}(t)-\lambda c T_{0}(t) .
\end{aligned}
$$

Denote as "solidarity function" $q(t)=\lambda\left[\left(e_{1} / r\right)\left(M_{0} / P_{0}\right)-c T_{0}(t)+v(t)\right]$; and "private initiative" by $p(t) \equiv \lambda\left[Z_{0}(t)-\left(e_{1} / r\right) j\right]$. Then the dynamics of income are

$$
\begin{aligned}
\dot{y}(t)-\lambda g(\dot{y}(t-h))= & -\lambda\left(1+\frac{e_{1} k}{r}-c\right) y(t)-\lambda\left(c f_{1}(y(t))+f_{2}(y(t))\right) \\
& +\lambda f_{3}(y(t-h))+p(t)+q(t) .
\end{aligned}
$$

It is an interconnected nonlinear system whose controllability is investigated for all values of $p$ and $q$.

It is proper to consider $x^{i}(t)=\left(x_{1}{ }^{i}(t), \ldots, x_{n}{ }^{i}(t)\right)$ to be the value of $n$ capital stocks with strategy $u^{i}=\left(u_{1}{ }^{i} \ldots u_{n}{ }^{i}\right),-1 \leq u_{j}{ }^{i}(t) \leq 1$, which are located in an isolated region $\left(S_{i}\right)$. They are linked to $l$ other such regional systems in the country and the "interconnection" or "solidarity functions", or government intervention given by

$$
q_{i}=q_{i}\left(x_{1 t}{ }^{i} \ldots x_{l t}{ }^{i}, u_{1 l^{i}} \ldots u_{l t}{ }^{i}\right) .
$$

Here $q_{i}$ describes the action of the whole system on its $i$ th interconnected subsystem $\left(S_{i}\right)$,

$$
\dot{x}^{i}(t)-A_{-1} \dot{x}^{i}(t-h)=A_{0} x^{i}(t)+A_{1} x^{i}(t-h)+B u^{i}(t) .
$$


Thus

$$
\dot{x}^{i}(t)-A_{-1} \dot{x}^{i}(t-h)=A_{0} x^{i}(t)+A_{1} x^{i}(t-h)+B u^{i}(t)+q_{i} .
$$

Thus formulated, we are interested in using the firm's strategy $\boldsymbol{u}^{i}$ and government interventions $q_{i}$, to control the growth of capital stock on which the wealth of a nation depends. Theorem 3.1 and Theorem 3.2 can be stated loosely as follows. If a regional economy is well behaved, carefully weighted government interventions $q_{i}$ can maintain the country's economic growth. Even if a regional economy is not controllable the intervention of solidarity function can render the system controllable. See Remark 3.1 and Theorem 3.2. Implications of controllability questions of neutral and other systems for the control of global economy are pursued elsewhere in [13], [14]. The issue of optimality is currently being investigated. Because of its apparent importance the author takes the rather general system of neutral type whose qualitative properties have been established by Hale and his school.

\section{Preliminaries}

The notations and definitions of [10] will be maintained as follows.

Let $E$ be the real line $(-\infty, \infty)$ and $E^{n}$ the Euclidean $n$-dimensional vector space. The symbol $L_{2}\left([a, b] E^{m}\right)$ denotes the usual Hilbert space of "square integrable" functions from $[a, b]$ into $E^{m}$. The Sobolev space $W_{2}{ }^{(1)}\left([a, b], E^{n}\right)=W_{2}{ }^{(1)}$ is the space of all absolutely continuous functions $x:[a, b] \rightarrow E^{n}$ with the property that $t \rightarrow \dot{x}(t)=(d x / d t)(t)$ belongs to $L_{2}\left([a, b], E^{n}\right)$.

Let $h>0$. Let $x$ be a function from $\left[\sigma-h, t_{1}\right] \rightarrow E^{n}$. Let $t \in\left[\sigma, t_{1}\right] \subset E$. We use $x_{t}$ to denote the function on $[-h, 0]$ defined by $x_{t}(\theta)=x(t+\theta),-h \leq \theta \leq 0$. The symbol $C=C\left([-h, 0] E^{n}\right)$ is the space of continuous functions from $[-h, 0] \rightarrow E^{n}$, with sup norm. We first consider systems of nonlinear functional differential equations of neutral type having the form

$$
\frac{d}{d t} D\left(t, x_{t}\right)=f\left(t, x_{t}, u(t)\right)+B(t) u(t),
$$

where the operator $D, D: E \times C \rightarrow E^{n}$ is atomic at 0 and uniformly atomic at 0 in the sense of Hale [21, pages 170-173], and where $f: E \times C \times E^{m} \rightarrow E^{n}$ is continuous and uniformly Lipschitzian in the last two arguments. We assume that $B(t)$ is a continuous $n \times m$ matrix function which is continuously differentiable, and the controls are $L_{2}$ functions. In (2.1), instead of the atomicity assumption on $D$, we may assume that $D$ is of the form

$$
D(t, \phi)=\phi(0)-g(t, \phi),
$$


where $g: E \times C \rightarrow E^{n}$ is continuous and is uniformly nonatomic at zero on $E \times C$ in the following sense.

DEFINITION 2.1. For any $(t, \phi) \in E \times C$, and $\mu \geq 0, s \geq 0$, let

$$
\begin{array}{r}
Q(t, \phi, \mu, s)=\{\psi \in C:(t, \psi) \in E \times C,\|\psi-\phi\| \leq \mu, \psi(\theta)=\phi(\theta), \\
\theta<-s, \theta \in[-h, 0]\} .
\end{array}
$$

We say that a continuous function $g: E \times C \rightarrow E^{n}$ is uniformly nonatomic at zero on $E \times C$ if, for any $(t, \phi) \in E \times C$, there exist $s_{0}>0, \mu_{0}>0$ independent of $(t, \phi)$, and a scalar function $\rho(t, \phi, \mu, s)$, defined and continuous for $(t, \phi), 0 \leq s \leq s_{0}$, $0 \leq \mu \leq \mu_{0}$, nondecreasing in $\mu, s$ such that

$$
\rho_{0}=\rho\left(E \times C, \mu_{0}, s_{0}\right)=\sup _{E \times C} \rho\left(t, \phi, \mu_{0}, s_{0}\right)<1
$$

and

$$
|g(t, \psi)-g(t, \phi)| \leq \rho_{0}\|\psi-\phi\|
$$

for $t \in E, \psi \in Q(t, \phi, \mu, s)$ and all $0 \leq s \leq s_{0}, 0 \leq \mu \leq \mu_{0}$.

It is known ([15], [21] and [23]) that under these assumptions on $D, f, B$ and $u$ for each $\phi \in C$ there is a unique solution of (2.1) with initial value $\phi$ at $\sigma$. The solution is continuous with respect to initial data and parameter $u$. For definition of solutions see [23]. In the sequel $t_{1}$ is fixed and is in the interval of definition $[\sigma, \tau]$, of solutions of (2.1).

DEFINITION 2.2. The system (2.1) is Euclidean controllable on $\left[\sigma, t_{1}\right]$ if for any function $\phi \in W_{2}{ }^{(1)}$ and any vector $x_{1} \in E^{n}$, there exists a control $u \in L_{2}\left(\left[\sigma, t_{1}\right], E^{m}\right)$ such that the solution $x(t)=x(t, \sigma, \phi, u)$ of (2.1) satisfies

$$
x_{\sigma}(\cdot, \sigma, \phi, u)=\phi, \quad x\left(t_{1}, \sigma, \phi, u\right)=x_{1} .
$$

It is Euclidean null controllable on $\left[\sigma, t_{1}\right]$ if $x_{1}=0$ in the above definition.

The system (2.1) is controllable on the interval $\left[\sigma, t_{1}\right], t_{1}>\sigma+h$ if for each $\phi, \psi \in W_{2}{ }^{(1)}$ there is a controller $u \in L_{2}\left(\left[\sigma, t_{1}\right], E^{m}\right)$ such that $x_{\sigma}(\cdot, \sigma, \phi, u)=\phi$, $x_{t_{1}}(\cdot, \sigma, \phi, u)=\psi$. It is null controllable on $\left[\sigma, t_{1}\right]$ if $\psi \equiv 0$ in the preceding definition.

In $W_{2}{ }^{(1)}$, we drop the qualifying phrase "on the interval $\left[\sigma, t_{1}\right]$ " if controllability obtains on every interval $[\sigma, t]$, with $t_{1}>\sigma+h$. In $E^{n}$ we drop "on the interval $\left[\sigma, t_{1}\right]$ " if Euclidean controllability holds on every interval $\left[\sigma, t_{1}\right], t_{1}>\sigma$. 
To motivate the problem, we consider a simple linear state equation of the $i$ th subsystem of a interconnected control system,

$$
\dot{x}^{i}(t)-A_{-1 i} \dot{x}^{i}(t-h)=A_{0 i} \dot{x}^{i}(t)+A_{1 i} x^{i}(t-h)+B_{i} u^{i}(t)+A_{2 i} y^{i}(t)+A_{3 i} y^{i}(t-h),
$$

where $x^{i}(t) \in E^{n_{i}}$ the $n_{i}$-dimensional Euclidean state vector of the $i$ th subsystem; $u^{i}(t) \in E^{m_{i}}$ is the control vector and $A_{-1 i}, A_{0 i}, A_{1 i}, A_{2 i}, A_{3 i}, B_{i}$ are time invariant matrices of appropriate dimensions. Furthermore, $y^{i}(t)$ is the supplementary variable of the $i$ th subsystem, and it is a function of its own Euclidean state vector $x^{i}(t)$ and other subsystems' state vector $x^{j}(t), j=1, \ldots, l$. This is expressed as follows:

$$
y^{i}(t)=M_{i i} x^{(i)}(t)+\sum_{j=1, j \neq i}^{l} M_{i j} x^{j}(t),
$$

where $M_{i i}, M_{i j}(j=1,2, \ldots, l)$ are constant matrices. On substituting (2.3) into (2.2), we deduce that the interconnected system has the equation

$$
\dot{x}^{i}(t)-A_{-1 i} \dot{x}(t-h)=H_{0 i} x^{i}(t)+H_{1 i} x^{i}(t-h)+B_{i} u^{i}(t)+h_{i}(t)+e_{i}(t-h),
$$

where

$$
\begin{aligned}
H_{0 i} & =A_{0 i}+A_{2 i} M_{i i}, & H_{1 i} & =A_{1 i}+A_{3 i} M_{i i}, \\
h_{i}(t) & =\sum_{j=1, j \neq i}^{l} M_{2 i} M_{i j} x^{j}(t), & e_{i}(t-h) & =\sum_{j=1, j \neq i}^{l} A_{e} i M_{i j} x^{j}(t-h) .
\end{aligned}
$$

In (2.4), the function $g_{i}(t, t-h) \equiv h_{i}(t)+e_{i}(t-h)$ describes the interaction, the effects of the whole system on the $i$ th subsystem. This can be measured locally. We may view the decomposed system (2.4) as an interconnection of $l$ isolated subsystems,

$$
\dot{x}^{i}(t)-A_{-1} \dot{x}^{i}(t-h)=H_{0 i} x^{i}(t)+H_{1 i} x^{i}(t-h)+B_{i} u^{i}(t),
$$

with an interconnection structure described by

$$
K_{i}(t, t-h)=h_{i}(t)+e_{i}(t-h),
$$

a function which does not depend on the state variable $x^{i}(t)$.

With this linear system as a guide, we consider the more general interconnected nonlinear system

$$
\frac{d}{d t} D_{i}\left(t, x_{t}{ }^{i}\right)=f_{i}\left(t, x_{t}{ }^{i}, u^{i}(t)\right)+B_{i}(t) u^{i}(t)+\sum_{j=1, j \neq i}^{l} K_{i j}\left(t, x_{t}{ }^{j}, v^{i}(t)\right),
$$

where

$$
D_{i}\left(t, x_{t}^{i}\right)=x^{i}(t)-g_{i}\left(t, x_{i}^{i}\right)
$$


and where $x_{t}^{i} \in C^{n_{i}}\left([-h, 0], E^{n_{i}}\right) \equiv C^{n_{i}}$ is the space of continuous functions from $[-h, 0]$ into $E^{n_{i}}$. We write $C^{n}=C\left([-h, 0], E^{n}\right)=C$. Equation (2.7) may be viewed as an interconnection of $l$ isolated free subsystems described by the equations

$$
\frac{d}{d t} D_{i}\left(t, x_{t}^{i}\right)=f_{i}\left(t, x_{t}^{i}, u^{i}(t)\right)+B_{i}(t) u^{i}(t),
$$

with interconnecting structure

$$
K_{i}\left(t, x_{i}, v^{i}\right)=\sum_{j=1, j \neq i}^{l} K_{i j}\left(t, x_{t}{ }^{j}, v^{i}(t)\right) .
$$

We assume $v^{i}$ is in a different control set from $u^{i}$. Here,

$$
\begin{aligned}
f_{i} & : E \times C^{n_{i}} \times E^{m_{i}} \rightarrow E^{n_{i}}, \\
K_{i j} & : E \times C^{n_{j}} \times E^{m_{i}} \rightarrow E^{n_{i}} .
\end{aligned}
$$

We let $n=\sum_{i=1}^{l} n_{i}, m=\sum_{i=1}^{l} m_{i}, x^{\top}=\left[\left(x^{\prime}\right)^{\top}, \ldots,\left(x^{l}\right)^{\top}\right] \in E^{n}$,

$$
\begin{aligned}
{\left[f\left(t, x_{t}, u\right)\right]^{\top} } & =\left[\left(f_{1}\left(t, x_{t}{ }^{1}, u^{1}\right)\right)^{\top} \ldots\left(f_{l}\left(t, x_{t}{ }^{\prime}, u^{l}\right)\right)^{\top}\right]^{\top}, \\
{\left[K\left(t, x_{t}, v\right)\right]^{\top} } & =\left[\left(K_{1}\left(t, x_{t}{ }^{1}, v^{1}\right)\right)^{\top} \ldots K_{l}\left(t, x_{t}{ }^{l}, v^{l}\right)\right]^{\top}, \\
B(t) & =\operatorname{diag}\left[B_{1}(t) \ldots B_{l}(t)\right], \\
D\left(t, x_{t}\right) & =\left[D,\left(t, x_{t}{ }^{1}\right)^{\top} \ldots D_{l}\left(t, x_{t}{ }^{i}\right)^{\top}\right] .
\end{aligned}
$$

With this notation, the decomposed system (2.7) can be represented by

$$
\frac{d}{d t} D\left(t, x_{t}\right)=f\left(t, x_{t}, u(t)\right)+B(t) u(t)+K\left(t, x_{t}, v(t)\right) .
$$

The free system (2.9) is given as in (2.1) by

$$
\frac{d}{d t} D\left(t, x_{t}\right)=f\left(t, x_{t}, u(t)\right)+B(t) u(t) .
$$

We assume in the sequel that $f, K, B$ and $D$ have the basic properties for the existence and uniqueness of solutions as well as the continuous dependence of solution on the initial data and parameter $u$.

\section{Main results}

In this section we maintain the notations of Section 2, and consider the free system

$$
\frac{d}{d t} D_{i}\left(t, x_{t}^{i}\right)=f_{i}\left(t, x_{t}^{i}, u^{i}(t)\right)+B_{i}(t) u^{i}(t)
$$


and the decomposed interconnected system

$$
\frac{d}{d t} D_{i}\left(t, x_{t}^{i}\right)=f_{i}\left(t, x_{t}^{i}, u^{i}(t)\right)+B_{i}(t) u^{i}(t)+K_{i}\left(t, x_{t}^{j}, v^{i}(t)\right),
$$

where $D_{i}, K_{i}$ are identified in (2.8) and (2.10) respectively. As observed, (3.2) can be represented by $(2.11)$, namely

$$
\frac{d}{d t} D\left(t, x_{t}\right)=f\left(t, x_{t}, u(t)\right)+B(t) u(t)+K\left(t, x_{t}, v(t)\right) .
$$

The first theorem is on the free subsystem (3.1). It extends the earlier paper [10] on Euclidean controllability to a result on function space controllability; it generalizes the more recent paper [7] by covering cases on which $f_{i}$ is not necessarily bounded.

THEOREM 3.1. In (3.1) assume that

(i) $\operatorname{rank} B_{i}(t)=n_{i}$ on $\left[t_{1}-h, t_{1}\right]$;

(ii) $B_{i}(t)$ is continuous on $\left[\sigma, t_{1}\right]$, with continuous derivative;

(iii) the function $g_{i}: E \times C \rightarrow E^{n_{i}}$ is uniformly nonatomic at zero on $E \times C^{n_{i}}$, and $f_{i}: E \times C \times E^{m} \rightarrow E^{n}$ is continuous;

(iv) the continuous functions $F_{i j}: C^{n_{i}} \times E^{m_{i}} \rightarrow E^{+}$and $L^{1}$ functions $\alpha_{i j}: E \rightarrow$ $E^{+}, j=1, \ldots, q$ are such that

$$
\left|f_{i}\left(t, \phi, u^{i}\right)\right| \leq \sum_{j=1}^{q} \alpha_{j}(t) F_{i j}\left(\phi, u^{i}\right) \quad \forall\left(t, \phi, u^{i}\right) \in E \times C \times E_{2}^{m_{i}},
$$

where

$$
\limsup _{r \rightarrow \infty}\left(r-\sum_{j=1}^{q} c_{j} \sup \left\{F_{i j}\left(\phi, u^{i}\right):\left\|\left(\phi, u^{i}\right)\right\| \leq r\right\}\right)=+\infty .
$$

Then (3.1) is controllable on $\left[\sigma, t_{1}\right]$ with $t_{1}>\sigma+h$.

In Theorem 3.1, Euclidean controllability of (3.1) is proved if we assume the condition

$$
\operatorname{rank}\left(H_{i}\left(t_{1}-\sigma\right)=\int_{0}^{t_{1}-\sigma} B(s) B^{*}(s) d s\right)=n \quad \text { for } t_{1}>\sigma
$$

instead of

$$
\operatorname{rank} B_{i}(t)=n \text { on }\left[t_{1}-h, t_{1}\right]
$$

of Theorem 3.1, condition (i).

The hypotheses (i)-(iv) are conditions on each subsystem which ensure controllability. We now state a result on the interconnected system. 
REMARK 3.1. Condition (ii) and (iii) are essentially the required criteria for the existence and uniqueness of solutions of (3.1). Condition (iv) is a growth condition which should be compared to a uniform bound imposed on $f$ by Mirza and Womack [29, Theorem $1 \mathrm{c}$ ] when treating delay equations. Such growth conditions have a long history: see Dauer [16], Chukwu [8], Balachandra and J.P. Dauer [3], and Do [19]. In Do [19], one sees the consequences of the growth condition.

THEOREM 3.2. In (3.2) assume

(i) all the conditions (i)-(iv) of Theorem 3.1;

(ii) for each $i, j=1, \ldots, l, i \neq j$ there are continuous functions $F i j: E^{n_{i}} \times$ $E^{m_{i}} \rightarrow E^{+}$and $L^{1}$ functions $\beta_{j}: E \rightarrow E^{+}, j=1, \ldots, q$ such that

$$
\left|K_{i}\left(t, \phi^{i}, v^{i}\right)\right| \leq \sum_{j=1}^{q} \beta_{j}(t) F_{i j}\left(\psi^{i}, u^{i}\right)
$$

for all $\left(t, \psi^{i}, u^{i}\right), \beta_{i}<\alpha_{i}$, where

$$
\limsup _{r \rightarrow \infty}\left(r-\sum_{j=1}^{q} c_{j} \sup \left\{F_{i j}\left(\psi^{i}, u^{i}\right):\left\|\left(\psi, u^{i}\right)\right\| \leq r\right\}\right)=+\infty .
$$

Then (3.2) is controllable on $\left[\sigma, t_{1}\right], t_{1}>\sigma+h$.

REMARK 3.2. Theorem 3.2 (ii) reminds one of the growth conditions in Michel and Miller [28, Theorem 5.8.4 (ii), Theorem 3.3.5 (iii), Theorem 3.3.2 (iii), Theorem 2.4.20 (iii)]. The condition 3.2 (ii) says that the external intervention $k_{i j}$ to the system is dominated by some "power" " $\beta_{j} F_{i j}$ " of the system.

REMARK 3.3. The nonlinearity and interconnectedness which are introduced in (2.10) and (2.11) are natural and essential in the economic application. In addition to the firm's initiative $p(t)=B(t) u(t)$ in (1.13), the control action of government $q(t)=\lambda\left[\left(e_{1} / r\right)\left(M_{0} / P_{0}\right)-c T_{0}(t)+v(t)\right]$, is (realistically) not linear in $M_{0}, P_{0}, T_{0}$ etc. The basic contribution of Lucas's critique [31] is that $p(t)$ must be incorporated. (See [31, Macroeconomics in the Global Economy, Chapter 19]). A deep reflection on Lucas's contribution demands a game theoretic formulation. This is the thrust of Mullinex's argument [30, page 91] and the reason for the insertion of a nontrivial $K_{i}$. It is also reasonable to have a nonlinear $f$. Investment and savings functions may be nonlinear, [30, page 87] (see (1.6), (1.7), (1.8), (1.9) and (1.2)). Of course results for the linear situation are already available in Chukwu [13]. Mathematicians often object to the full rank of $B$, but the economic insight of Tinbergen in [31, pages 5, 90] shows how essential this "classical" nondegeneracy assumption is in executing monetary and fiscal policies. 
That $K_{i}$ is assumed to be sufficiently "small" compared to the linearly acting control is nothing but a nonlinear generalization of the requirement in the linear pursuit game $\dot{y}(t)-a_{-1} \dot{y}(t-h)=a_{0} y(t)+a_{1} y(t-h)+p(t)+q(t), \quad p(t) \in P, q(t) \in Q$ that

$$
\text { Int } P \supset Q \text { : }
$$

the firm's control set (or initiative) should dominate the government's. This is a necessary and sufficient condition (on the control sets) for controllability. See Hájek [20, page 61] for the genesis of this idea. It settles a basic problem: how much (in comparison with private effort) should government intervention be in the economy.

PROOF. Under the conditions of the theorem, the system (3.1) is Euclidean controllable. Indeed, let $x_{1}^{i} \in E^{n_{i}}, \phi^{i} \in C^{n_{i}}$ then the solution $x^{i}$ of (3.1) is given by

$$
\begin{aligned}
x^{i}(t+\sigma)= & \phi^{i}(t) \quad t \in[-h, 0] \\
x^{i}(t)= & D_{i}\left(\sigma, \phi^{i}\right)+g_{i}\left(t, x_{t}^{i}\right) \\
& +\int_{\sigma}^{t} f_{i}\left(s, x_{s}^{i}, u^{i}(s)\right) d s+\int_{\sigma}^{l} B_{i}(s) u^{i}(s) d s, \quad t \geq \sigma .
\end{aligned}
$$

From (i) with $B_{i}{ }^{*}$ the algebraic adjoint of $B_{i}, B_{i}(t) B_{i}{ }^{*}(t)$ has rank $n_{i}$ on $\left[t_{1}-h, t_{1}\right]$ so that $H_{i}\left(t_{1}\right)=\int_{\sigma}^{t_{1}} B_{i}(s) B_{i}^{*}(s) d s$ has rank $n_{i}$, for $t_{1}>\sigma+h$, since

$$
H_{i}\left(t_{1}\right)=\int_{\sigma}^{t_{1}-h} B_{i}(s) B_{i}^{*}(s) d s+\int_{t_{1}-h}^{t_{1}} B_{i}(s) B_{i}^{*}(s) d s
$$

and the last term is positive definite. As a consequence of this,

$$
H_{i}\left(t_{1}-\sigma\right)=\int_{\sigma}^{t_{1}-\sigma} B(s+\sigma) B^{*}(s+\sigma) d s
$$

is nonsingular for a carefully chosen $t_{1}$ (e.g. $t_{1}>2 \sigma+h$ ). The solution of (3.1) with $u^{i}$ as a control is given by (3.4). Let $x^{i} \in C\left([\sigma-h, \tau], E^{n_{i}}\right)$. Define

$$
\begin{aligned}
& \bar{x}_{\sigma}^{i}(t)=x^{i}(t) \quad t \in[\sigma-h, \sigma], \\
& \bar{x}_{\sigma}^{i}(t)=x^{i}(\sigma) \quad t \in[\sigma, \sigma+\tau],
\end{aligned}
$$

and define $\bar{\phi}^{i}:[-h, \infty) \rightarrow E^{n_{i}}$, by

$$
\begin{aligned}
\bar{\phi}(t) & =\phi^{i}(t) \quad t \in[-h, 0], \\
\bar{\phi}^{i}(t) & =\phi^{i}(0)
\end{aligned}
$$


It follows from these definitions and from (3.4) that $x^{i}$ is a solution of (3.1) on $[\sigma, \sigma+\tau], 0 \leq \tau<\infty$, if and only if

$$
x^{i}(\sigma+t)=\bar{\phi}^{i}(t)+z^{i}(t), \quad-h \leq t \leq \tau,
$$

where $z^{i}(t)$ satisfies

$$
\begin{gathered}
z^{i}(t)=g_{i}\left(t+\sigma, \bar{\phi}_{t}^{i}+z_{t}^{i}\right)-g_{i}\left(\sigma, \phi^{i}\right)+\int_{0}^{t} f_{i}\left(s+\sigma, \phi_{s}^{i}+z_{s}^{i}, u^{i}(s+\sigma)\right) d s \\
+\int_{0}^{t} B_{i}(s+\sigma) u^{i}(s+\sigma) d s, \quad z_{0}^{i}=0 .
\end{gathered}
$$

Note that if $t_{1} \in[\sigma, \tau]$, then $x^{i}\left(t_{1}\right)=x_{1}^{i}$ if and only if

$$
z^{i}\left(t_{1}-\sigma\right)=x_{1}^{i}-\bar{\phi}^{i}\left(t_{1}-\sigma\right) .
$$

The corresponding $u^{i}$ which steers $\phi^{i}$ to $x_{1}^{i}$ in time $t_{1}$ is given by

$$
\begin{aligned}
u^{i}(t)= & B_{i}^{*}(t) H_{i}^{-1}\left(t_{1}-\sigma\right)\left(x_{1}^{i}-\bar{\phi}^{i}\left(t_{1}-\sigma\right)+g_{i}(\sigma, \phi)\right. \\
& \left.-g_{i}\left(t_{1}, \bar{\phi}_{t_{1}}^{i}-\sigma+z_{t_{1}}^{i}-\sigma\right) \int_{0}^{t_{1}-\sigma} f_{i}\left(s+\sigma, \bar{\phi}_{s}^{i}+z_{s}^{i}, u^{i}(s+\sigma)\right) d s\right) .
\end{aligned}
$$

We need the following lemmas.

LEMMA 3.1. (Hale and Cruz, [23, page 70]) Let $U$ be an open set in $I \times C_{1}^{n_{i}} \times$ $C_{2}\left(\left[\sigma, t_{1}\right], E^{m_{i}}\right)$ and let $V$ be its projection on $I \times C_{1}^{n_{i}}$, where $C_{1}^{n_{i}}=C_{1}\left([-h, 0], E^{n_{i}}\right)$. Let $W=\left\{\left(\sigma, x_{\sigma}, u(\sigma)\right)\right\}$. Let $U_{\epsilon}(W)$ be an $\epsilon$-neighbourhood of $W \subseteq U$. Let $f_{i}: U \rightarrow E^{n_{i}}$ be continuous, $\left|f_{i}\right| \leq M$ on $U_{\epsilon}(W)$ and $g_{i}: V \rightarrow E^{n_{i}}$ nonatomic at zero. There are positive real numbers $\gamma_{0}, \delta_{0}, \delta$, $v$ and $t_{1}, 0<t_{1} \leq \delta_{0}, 0<\delta<\delta_{0} / 2$, such that

(i) (a) $M t_{1}<v \delta / 2$ or $\quad$ (b) $M t_{1}<(v(1-v) \delta / 2)$;

(ii) $\left\|\bar{x}_{\sigma t}-x_{\sigma}\right\|<\delta_{0} / 2, t \in\left[\sigma, \sigma+t_{1}\right]$;

(iii) $\left|g\left(t, \bar{x}_{\sigma t}\right)-g\left(\sigma, x_{\sigma}\right)\right|<v \delta / 2, t \in\left[\sigma, \sigma+t_{1}\right]$;

(iv) $\rho\left(t, \psi, \delta_{0}, \gamma_{0}\right) \leq 1-v<1$ for $(t, \psi) \in F\left(\gamma_{0}, \delta_{0}\right)$, where

$$
F\left(\gamma_{0}, \delta_{0}\right)=\left\{(t, \psi) \in E \times C\left([-h, 0], E^{n}\right) \quad t \in\left[\sigma, \sigma+\delta_{0}\right],\left\|\psi-x_{\sigma}\right\| \leq \delta_{0}\right\} ;
$$

(v) $F\left(\gamma_{0}, \delta_{0}\right) \subseteq V$.

LEMMA 3.2. Let $B: I \rightarrow E^{n \times m}$ be a continuous $n \times m$ matrix function. Then the constants $t_{1}, v$ in Lemma 3.1 can be chosen such that

$$
(1-v)\left(1+\left\|B^{*}(t) H^{-1}\left(\sigma, t_{1}-\sigma\right)\right\|<1 .\right.
$$


We now prove that such a $u^{i}$ in (3.6) exists. Now set

$$
\begin{aligned}
& T\left(z^{i}, u^{i}\right)(t)=0 \quad \text { if } t \in[-h, 0] ; \\
& S\left(z^{i}, u^{i}\right)(t)=0 \quad \text { if } t \in[-h, 0] ; \\
& T\left(z^{i}, u^{i}\right)(t)=(y(t), w(t)) \quad \text { if } t \in[0, \tau] ; \\
& S\left(z^{i}, u^{i}\right)(t)=(h(t), v(t)) \quad \text { if } t \in[0, \tau],
\end{aligned}
$$

where

$$
\begin{aligned}
y(t) & =g_{i}\left(t+\sigma, \bar{\phi}_{t}^{i}+z_{t}^{i}\right)-g_{i}\left(\sigma, \phi^{i}\right) \\
h(t) & =\int_{0}^{t} f_{i}\left(s+\sigma, \bar{\phi}_{s}^{i}+z_{s}^{i}, u^{i}(s+\sigma)\right) d s+\int_{\sigma}^{t} B_{i}(s+\sigma) u^{i}(s+\sigma) d s \\
w(t) & =B_{i}^{*}(t) H_{i}^{-1}\left(t_{1}-\sigma\right)\left(x_{1}^{i}-\bar{\phi}^{i}\left(t_{1}-\sigma\right)+g_{i}\left(\sigma, \phi^{i}\right)-g_{i}\left(t_{1}, \bar{\phi}_{t_{1}-\sigma}^{i}\right)\right) \\
v(t) & =-B_{i}{ }^{*}(t) H_{i}^{-1}\left(t_{1}-\sigma\right) \int_{0}^{t_{1}-\sigma} f_{i}\left(s+\sigma, \bar{\phi}_{s}^{i}+z_{s}{ }^{i}, u^{i}(s+\sigma)\right) d s .
\end{aligned}
$$

Recall that $t_{1} \in[\sigma, t]$. From the earlier remarks, it is clear that if an operator $T+S$ given by

$$
(T+S)\left(z^{i}, u^{i}\right)(t)=(y(t)+h(t), w(t)+v(t))
$$

has a fixed point, so that

$$
(T+S)\left(z^{i}, u^{i}\right)(t)=\left(z^{i}(t), u^{i}(t)\right),
$$

then (3.1) is Euclidean controllable. In this case $z^{i}(t)$ is given by (3.5) and $u^{i}(t)$ by (3.6), so that

$$
\begin{aligned}
z^{i}\left(t_{1}-\sigma\right)= & g_{i}\left(t_{1}, \bar{\phi}_{t_{1}-\sigma}^{i}+z_{t_{1}-\sigma}{ }^{i}\right)-g_{i}\left(\sigma, \phi^{i}\right)+\int_{0}^{t_{1}-\sigma} f_{i}\left(s+\sigma, \bar{\phi}_{s}^{i}+z_{s}{ }^{i}, u^{i}(s+\sigma)\right) d s \\
+ & +\int_{0}^{t_{1}-\sigma} B_{i}(s+\sigma) B_{i}{ }^{*}(s+\sigma) d s \\
& \times H_{i}{ }^{-1}\left(x_{1}{ }^{i}-\bar{\phi}^{i}\left(t_{1}-\sigma\right)+g_{i}\left(\sigma, \phi^{i}\right)-g_{i}\left(t_{1}, \bar{\phi}_{t_{1}-\sigma}^{i}+z_{t_{1}-\sigma}{ }^{i}\right)\right. \\
& \left.\quad-\int_{0}^{t_{1}-\sigma} f_{i}\left(s+\sigma, \bar{\phi}_{s}^{i}+z_{s}{ }^{i}, u^{i}(s+\sigma)\right) d s\right) \\
= & x_{1}{ }^{i}-\bar{\phi}^{i}\left(t_{1}-\sigma\right) .
\end{aligned}
$$

That is,

$$
z^{i}\left(t_{1}-\sigma\right)=x_{1}^{i}-\bar{\phi}^{i}\left(t_{1}-\sigma\right)
$$


or

$$
x_{1}^{i}=z^{i}\left(t_{1}-\sigma\right)+\bar{\phi}^{i}\left(t_{1}-\sigma\right)=x^{i}\left(t_{1}\right) .
$$

Our immediate aim now is to establish the existence of a fixed point of $T+S$ in an appropriate function space. Introduce the following space:

$$
X=C\left(\left[-h, t_{1}\right], E^{n_{i}}\right) \times L_{2}\left(\left[0, t_{1}\right], E^{m_{i}}\right)
$$

with norm

$$
\|(\phi, u)\|=\|\phi\|+\|u\|_{2},
$$

where $\|\phi\|=\sup _{s \in\left[-h, t_{1}\right]}|\phi(s)|$, and $\|u\|_{2}$ is the $L_{2}$ norm of $u$. We show that there is a positive constant $r_{0}$ and a subset $A$ of $X$ such that

$$
A=A_{1}\left(t_{1}, r_{0}\right) \times A_{2}\left(t_{1}, r_{0}\right),
$$

where

$$
\begin{aligned}
& A_{1}\left(t_{1}, \bar{r}_{0}\right)=\left\{\zeta:\left[-h, t_{1}\right] \rightarrow E^{n_{i}} \text { continuous, } \zeta_{0}=0,\left\|\zeta_{t}\right\| \leq r_{0}, t \in\left[0, t_{1}\right]\right\} \\
& A_{2}\left(t_{1}, r_{0}\right)=\left\{u \in L_{2}\left(\left[0, t_{1}\right], E^{m_{i}}\right):|u(t)| \leq r_{0} \quad \text { a.e. in } t \in\left[0, t_{1}\right]\right\}
\end{aligned}
$$

Also $T: A \rightarrow A$ is a contraction; and $S: A \rightarrow A$ is completely continuous, and $T+S: A \rightarrow A$. With this a fixed point is established by virtue of [10, Lemma 1.1] Most of the details are as contained in [10, Theorem 2.1]. Indeed, let

$$
F_{i j}(r)=\sup \left\{F_{i j}(\phi, u):\|(\phi, u)\| \leq r\right\} .
$$

Since the growth condition in (iv) is valid, there exists a constant $r_{0}>0$ such that

$$
r_{0}-\sum_{j=1}^{q} c_{i} F_{i j}\left(r_{0}\right) \geq d
$$

or

$$
\sum_{j=1}^{q} c_{i} F_{i j}\left(r_{0}\right)+d \leq r_{0},
$$

(see [19, page 44]). By direct calculations and estimates contained in [10, pages 121122] we easily show that if $\left(z_{j}{ }^{i}, u_{j}{ }^{i}\right) \in A, j=1,2, T\left(z_{1}{ }^{i}, u_{1}{ }^{i}\right)(t)+S\left(z_{2}{ }^{i}, u_{2}{ }^{i}\right)(t)=0$, $t \in[-h, 0]$. Also

$$
\left|T\left(z_{1}{ }^{i}, u_{1}{ }^{i}\right)(t)+S\left(z_{2}{ }^{i}, u_{2}{ }^{i}\right)\right| \leq|y(t)|+|h(t)|+|w(t)|+|v(t)|,
$$

where

$$
\begin{aligned}
|y(t)| & \leq\left|g\left(t+\sigma, \bar{\phi}_{t}+z_{1 t}\right)-g\left(t+\sigma, \bar{\phi}_{t}\right)\right|+\left|g\left(t+\sigma, \bar{\phi}_{t}\right)-g(\sigma, \phi)\right| \\
& \leq \rho\left(t+\sigma, \bar{\phi}_{t-\sigma}, s, t_{1}\right) \delta+v \delta / 2 \\
& \leq(1-v) \delta+v \delta / 2=\delta-v \delta / 2,
\end{aligned}
$$


and we have used Lemma 1.2 of Hale [23] where $v, \delta$ are identified in Lemma 3.1. Also

$$
\begin{aligned}
|h(t)| & \leq \int_{0}^{t}\left|f_{i}\left(s+\sigma, \bar{\phi}_{s}+z_{2 s}, u_{2}(s+\sigma)\right)\right| d s+\int_{0}^{t}\left|B_{i}(s+\sigma) u_{2}(s+\sigma)\right| d s \\
& \leq \sum_{i=1}^{q} \int_{0}^{t} \alpha_{j}(s+\sigma) F_{i j}\left(\bar{\phi}_{s}+z_{2 s} u_{2}(s+\sigma)\right) d s+N v \underline{q} \\
& \leq N v \underline{q}+\sum_{j=1}^{q}\left\|\alpha_{j}\right\| F_{i j}\left(r_{0}\right),
\end{aligned}
$$

where $N=\max _{s \in\left\{0, t_{1}\right]}\left\|B_{i}(s+\sigma)\right\|$ and $\left\|\alpha_{j}\right\|=\int_{0}^{t_{1}}\left|\alpha_{j}(s+\sigma)\right| d s$. Hence

$$
\begin{aligned}
|y(t)|+|h(t)| & \leq(1-v / 2) \delta+N v \underline{q}+\sum_{j=1}^{q}\left\|\alpha_{j}\right\| F_{i j}\left(r_{0}\right) \\
& \leq d_{1}+\sum_{j=1}^{q}\left\|\alpha_{j}\right\| F_{i j}\left(r_{0}\right) \leq r_{0},
\end{aligned}
$$

where

$$
\begin{aligned}
& d_{1}=\max \left\{(1-v / 2) \delta+N v \underline{q},\left\|B^{*}(t) H^{-1}\right\|\left(\left|x_{1}-\bar{\phi}(t, \sigma)\right|\right)+(1-v / 2) \delta\right\} \\
& c_{i}=\max \left\{\left\|\alpha_{j}\right\|,\left\|B^{*} H^{-1}\right\|\left\|\alpha_{j}\right\|\right\} .
\end{aligned}
$$

Hence

$$
\|y\|+\|h\| \leq r_{0}
$$

Now

$$
\begin{aligned}
|w(t)| & \leq\left\|B^{*}(t) H^{-1}\right\|\left(\left|x_{1}-\bar{\phi}\left(t_{1}-\sigma\right)\right|\right)+\mid g\left(t_{1}, \bar{\phi}_{t_{1}-\sigma}+z_{t_{1}-\sigma}-g\left(t_{1}, \bar{\phi}_{t_{1}-\sigma}\right) \mid\right. \\
& +\left|g\left(t_{1}, \bar{\phi}\left(t_{1}-\sigma\right)\right)-g(\sigma, \phi)\right| \\
& \leq\left\|B^{*}(t) H^{-1}\right\|\left(\mid x_{1}-\bar{\phi}\left(t_{1}-\sigma\right) \|\right)+\rho\left(t_{1}, \bar{\phi}_{t_{1}-\sigma}, \delta, t_{1}\right) \delta+v \delta / 2 \\
& \leq(1-v) \delta+v \delta / 2+\left\|B^{*} H^{-1}\right\|\left(\left|x_{1}-\bar{\phi}\left(t_{1}-\sigma\right)\right|\right) .
\end{aligned}
$$

Also

$$
\begin{aligned}
|v(t)| & \leq\left\|B^{*}(t) H^{-1}\right\| \int_{0}^{f_{1}-\sigma}\left|H\left(s+\sigma, \bar{\phi}_{s}^{i}+z_{s}{ }^{i}, u^{i}(s+\sigma)\right)\right| d s \\
& \leq\left\|B^{*}(t) H^{-1}\right\|\left(\int_{0}^{t_{1}-\sigma} \sum_{j=1}^{q}\left|\alpha_{j}\right| F_{i j}\left(r_{0}\right)\right) \\
& \leq\left\|B H^{-1}\right\| \sum_{j=1}^{q}\left\|\alpha_{j}\right\| F_{i j}\left(r_{0}\right)
\end{aligned}
$$


where $\int_{0}^{t_{1}-\sigma}\left|\alpha_{j}\right|=\left\|\alpha_{j}\right\|$. Thus

$$
\begin{gathered}
|w(t)|+|v(t)| \leq(1-v) \delta+\delta / 2 v+\left\|B^{*} H^{-1}\right\|\left(\left|x_{1}-\bar{\phi}\left(t_{1}-\sigma\right)\right|\right) \\
+\left\|B H^{-1}\right\| \sum_{j=1}^{q}\left\|\alpha_{j}\right\| F_{i j}\left(r_{0}\right) \\
\leq d_{1}+\sum_{j=1}^{q} c_{j} F_{i j}\left(r_{0}\right) \leq r_{0} .
\end{gathered}
$$

We have proved that $T+S: A \rightarrow A$. It is clear that $S$ is continuous and $S: A \rightarrow A$. That $S$ is compact is due to the following arguments.

$$
\begin{aligned}
\left|S\left(z^{i}, u^{i}\right)(t)-S\left(z^{i}, u^{i}\right)\left(t^{1}\right)\right| & =\left|h(t)-h\left(t^{1}\right)\right|+\left|v(t)-v\left(t^{\prime}\right)\right| \\
& \leq M\left|t-t^{1}\right|+N r_{0}\left|t-t^{1}\right|+\left|B_{i}^{*}(t)-B_{i}^{*}{ }^{*}\left(t^{\prime}\right)\right| G \\
& \leq \rho\left|t-t^{1}\right| \quad \text { for } t, t^{1} \in J,
\end{aligned}
$$

where

$$
\begin{aligned}
G & =\left\|H_{i}{ }^{-1}\right\| M\left(t_{1}-\sigma\right), \\
M & =\max _{s \in\left[0, t_{1}\right]}\left|f_{i}\left(s+\sigma, \bar{\phi}_{s}^{i}+z_{s}{ }^{i}, u^{i}(s+\sigma)\right)\right|, \\
N & =\max _{s \in\left[0, t_{i}\right]}\left\|B_{i}(s+\sigma)\right\|, \\
\rho & =M+N M+m n c, \\
c & =\max _{i, j} \max _{0 \leq t \leq T} \frac{d b_{i j}{ }^{*}}{d t},\left(b_{i j}{ }^{*}\right)=B^{*} .
\end{aligned}
$$

We now prove that $T$ is a contraction. Let $\left(z_{j}{ }^{i}, u_{j}{ }^{i}\right) \in A, j=1,2$. Then

$$
\underline{M} \equiv\left|T\left(z_{1}{ }^{i}, u_{1}{ }^{i}\right)(t)-T\left(z_{2}{ }^{i}, u_{2}{ }^{i}\right)(t)\right| \leq\left|y_{1}(t)-y_{2}(t)\right|+\left|w_{1}(t)-w_{2}(t)\right| .
$$

But

$$
\begin{aligned}
\left|y_{1}(t)-y_{2}(t)\right| & \leq\left|g\left(t+\sigma, \bar{\phi}_{t}+z_{1 t}^{i}\right)-g\left(t+\sigma, \bar{\phi}_{i}+z_{2 t}^{i}\right)\right| \\
& \leq \rho\left(t+\sigma, \bar{\phi}_{t}+z_{2 t}^{i}, \delta, t_{1}\right)\left\|z_{2 t}{ }^{i}-z_{1 t}^{i}\right\| \\
& \leq(1-v)\left\|z_{2 t}^{i}-z_{1 t}^{i}\right\|,
\end{aligned}
$$

where $\|\cdot\|$ is the norm in $A_{1}$ and we have used the nonatomicity of $g$ as was done in Chukwu [10, page 120]. Also

$$
\begin{aligned}
\left|w_{1}(t)-w_{2}(t)\right| & \leq\left\|B^{*}(t) H^{-1}\right\|\left(\left|g\left(t, \bar{\phi}_{t-\sigma}+z_{2 t-\sigma}^{i}\right)-g\left(t, \bar{\phi}_{t-\sigma}+z_{1 t-\sigma}\right)\right|\right) \\
& \leq\left\|B^{*}(t) H^{-1}\right\|\left\{(1-v)\left\|z_{2 t-\sigma}^{i}-\left(z_{1 t-\sigma}^{i}\right)\right\|\right\} \\
& \leq\left\|B^{*}(t) H^{-1}\right\|\left\{(1-v)\left\|z_{2 t-\sigma}^{i}-z_{1 t-\sigma}^{i}\right\|\right\} .
\end{aligned}
$$


We have obtained

$$
\left|w_{1}(t)-w_{2}(t)\right| \leq\left\|B^{*}(t) H^{-1}\right\|\left\{(1-v)\left\|z_{1 t-\sigma}^{i}-z_{2 t-\sigma}^{i}\right\|\right\} .
$$

As a consequence of these calculations,

$$
\underline{M} \leq \pi\left\{\left\|z_{1,}^{i}-z_{2 \ell}^{i}\right\|\right\}
$$

where

$$
\pi=\left\{(1-v)\left(1+\left\|B^{*}(t) H^{-1}\right\|\right)\right\} .
$$

Because $v$ can be chosen so that the sum $\pi$ is less than 1 , we have proved that $T$ is a contraction. We use Lemma 1.1 of [10] to assert, that $T+S$ has a fixed point which proves that

$$
x^{i}\left(t_{1}\right)=x_{1}^{i}=z^{i}\left(t_{1}-\sigma\right)+\bar{\phi}^{i}\left(t_{1}-\sigma\right)
$$

and any $\phi^{i} \in W_{2}{ }^{(1)}$ can be transferred to $x_{1}{ }^{i} \in E^{n}$ in time $t_{1}$. Thus (3.1) is Euclidean controllable on $\left[\sigma, t_{1}\right]$. The same argument proves that (3.1) is Euclidean controllable on $\left[\sigma, t_{1}-h\right]$, since $B(t)$ is continuous. Indeed, since $B_{i}$ is continuous and $B_{i}\left(t_{1}-\right.$ h) $B^{*}(t-h)$ has rank $n$, there is an $\epsilon>0$ such that $B_{i}\left(t_{1}-h-\epsilon\right) B_{i}^{*}\left(t_{1}-h-\epsilon\right)$ has rank $n$ and $B_{i}(t-h-s) B_{i}^{*}(t-h-s)$ has rank $n$ for all $s \in[0, \epsilon]$. Therefore

$$
\begin{aligned}
H\left(t_{1}-h\right) & =\int_{\sigma}^{t_{i}-h} B_{i}(s) B_{i}^{*}(s) d s \\
& =\int_{\sigma}^{t_{1}-h-\epsilon} B_{i}(s) B_{i}^{*}(s) d s+\int_{i-h-\epsilon}^{t_{1}-\epsilon} B_{i}(s) B_{i}^{*}(s) d s
\end{aligned}
$$

is positive definite. As argued before, (3.1) is Euclidean controllable on $\left[\sigma, t_{1}-h\right]$. Because of this, given $\phi^{i}, \psi^{i} \in W_{2}{ }^{(1)}\left([-h, 0], E^{n_{i}}\right)$ there exists a $u \in L_{2}\left(\left[\sigma, t_{1}-\right.\right.$ $\left.h], E^{m_{i}}\right)$ such that $x_{\sigma}{ }^{i}=\phi$ and $x^{i}\left(t_{1}-h, \sigma, \phi^{i}, u\right)=\psi^{i}(-h)$. We extend this $u$ and $x^{i}\left(\cdot, \sigma, \phi_{1}^{i}, u\right)$ to the interval $\left[\sigma, t_{1}\right], t_{1}>\sigma+h$, so that

$$
\frac{d}{d t}\left(D_{i}\left(t, x_{t}^{i}\right)\right)=f_{i}\left(t, x_{t}^{i}, u(t)\right)+B_{i}(t) u(t)
$$

on $\left[t_{1}-h, t_{1}\right]$ where $x(t)=\psi\left(t-t_{1}\right), t_{1}-h \leq t \leq t_{1}$, on the right-hand side of (3.7). In view of hypothesis (i) we define a control $u$ as follows,

$$
u(t)=B_{i}^{+}(t)\left(\frac{d}{d t}\left(D_{i}\left(t, x_{t}^{i}\right)-f_{i}\left(t, x_{t}^{i}, u(t)\right)\right),\right.
$$

for $t_{1}-h \leq t \leq t_{1}$, where $B_{i}^{+}$is the generalized inverse of $B_{i}$. With this $u, x$ satisfies (3.7). Indeed insert $u$ defined by (3.8) in (3.7):

$$
\begin{aligned}
\frac{d}{d t} D_{i}\left(t, x_{t}^{i}\right) & =f_{i}\left(t, x_{t}^{i}, u(t)\right)+B_{i}(t) B_{i}^{+}(t)\left(\frac{d}{d t} D_{i}\left(t, x_{t}^{i}\right)-f_{i}\left(t, x_{t}^{i}, u(t)\right)\right) \\
& =\frac{d}{d t} D_{i}\left(t, x_{t}^{i}\right),
\end{aligned}
$$


with $x(t)=\psi\left(t-t_{1}\right), t_{1}-h \leq t \leq t_{1}$. Evidently $u$ is square integrable on $\left[t_{1}-h, t_{1}\right]$ because of hypothesis (ii) and the continuity of $f_{i}, x$ and $\psi$. We now prove that $u$ is well-defined as a solution of the functional equation (3.8). We now define the following set:

$$
\begin{aligned}
& A \equiv A_{1}\left(r_{0}\right)=\left\{u \in L_{2}\left(\left[t_{1}-h, t_{1}\right], E^{m}\right):|u(t)| \leq r_{0} \quad \text { a.e. and } v \in A\right. \text { implies } \\
&\left.\int_{t_{1}-h}^{t_{1}}|v(t+s)-v(t)|^{2} d t \rightarrow 0 \text { as } s \rightarrow 0 \text { uniformly with } v \in A\right\} .
\end{aligned}
$$

By [13, page 297], $A$ is compact. Define an operator $T(u)(t)=v(t)$ where

$$
v(t)=B_{i}{ }^{+}(t)\left(\frac{d}{d t} D\left(t, \psi_{t-t_{1}}\right)-f\left(t, x_{t}^{i}, u(t)\right)\right) .
$$

We now show that there is a constant $r_{0}$ and a Banach space $A \equiv A\left(r_{0}\right)$ such that $T: A \rightarrow A$ where $T$ is continuous. Thus we are guaranteed a fixed point $T(u)=$ $(u) \in A$ which proves that (3.8) holds. The existence of a fixed point follows from [25, page 297] and [25, page 645] because $A$ is compact convex subset of the Banach space $L_{2}$. To demonstrate the validity of our assertions, we observe that by (i) and (ii), the generalized inverse $B_{i}^{+}(t)$ is continuous [6, page 225], and is therefore uniformly bounded on $\left[t_{1}-h, t_{1}\right]$. Also $D_{i}\left(t, x_{t}\right)$ is differentiable wit $\mathrm{h}$ an $L_{2}$ derivative. Let $(u) \in A$. Since the growth condition (iv) is valid there exists $r_{0}>0$ such that

$$
\sum_{j=1}^{q} c_{j} F_{i j}\left(r_{0}\right)+d \leq r_{0},
$$

for some $d$. With this $r_{0}$, define $A=A\left(r_{0}\right)$. Now introduce the following notations

$$
\begin{aligned}
\beta & =\max \left\{\|B(t, \phi)\|: \sigma \leq t \leq t_{1}\right\}, \\
\beta^{+} & =\max \left\{\left\|B^{+}(t, \phi)\right\|: \sigma \leq t \leq t_{1}\right\}, \\
b & =\max \left\{\beta, \beta^{+}\right\}, \\
k & =\max \left\{\beta\left(t_{1}-\sigma\right), 1, b\right\}, \\
\lambda & =\max \left\{\beta^{+}\left\|H^{-1}\right\|,\left\|B_{i}^{*} H_{i}^{-1}\right\|\right\}, \\
\left\|\alpha_{i}\right\| & =\max \left\{\int_{\sigma}^{t_{1}}\left|\alpha_{i}(s)\right| d s,\left\|\alpha_{i}\right\|_{2}, \sup _{t}\left|\alpha_{j}(t)\right|\right\}, \\
a_{i} & =3 k \lambda\left\|\alpha_{i}\right\|, \\
b_{i} & =3\left\|\alpha_{i}\right\|, \\
c_{i} & =\max \left\{a_{i}, b_{i}\right\}, \\
d_{2} & =\max \left\{3 k \lambda\left\|\dot{D}\left(\psi_{t-t_{1}}\right)\right\|_{2}, \sup _{t}\left|\dot{D}\left(\psi_{t-t_{1}}\right)\right|\right\}, \\
d & =\max \left\{d_{1}, d_{2}\right\} .
\end{aligned}
$$


Since $u \in A$, we have $|T(u)(t)| \leq|v(t)|$, where

$$
\begin{aligned}
|v(t)| & \leq\left|B^{+}\left(t, x_{t}^{u}\right)\right|\left(\left|\frac{d}{d t} D\left(t, \psi_{t-t_{1}}\right)-f_{i}\left(t, x_{t-t_{1}}, u(t)\right)\right|\right) \\
& \leq \beta^{+}\left(\left|\dot{D}\left(t, \psi_{t-t_{1}}\right)\right|+\left|f_{i}\left(t, x_{t}^{i}, u^{i}(t)\right)\right|\right) \\
& \leq \beta^{+}\left(\left|\dot{D}\left(t, \psi_{t-t_{1}}\right)\right|+\sum_{j=1}^{q} \alpha_{j}(t) F_{i j}\left(x_{t}^{i}, u^{i}(t)\right)\right) \\
& \leq \beta^{+}\left(\left|\dot{D}\left(t, \psi_{t-t_{1}}\right)\right|+\sum_{j=1}^{q}\left|\alpha_{j}(t)\right| F_{i j}\left(r_{0}\right)\right) \\
& \leq \frac{d_{2}}{3 k}+\sum_{j=1}^{q} \frac{1}{3 k} \alpha_{j} F_{i j}\left(r_{0}\right) \leq \frac{1}{3 k}\left(d_{2}+\sum_{j=1}^{q} c_{j} F_{i j}\left(r_{0}\right)\right) \\
& \leq \frac{1}{3 k} r_{0} \leq \frac{r_{0}}{3} .
\end{aligned}
$$

Hence $|T(u)(t)| \leq r_{0}$. We have proved that $T: A \rightarrow A$ provided the second condition is satisfied. To verify the second condition we note that

$$
\left.\int_{t_{1}-h}^{t_{1}}|T(u)(t+s)-T(u)(t)|^{2} d t=\int_{t_{1}-h}^{t_{1}} \mid B_{i}^{+}(t+s) \lambda(t+s)-B_{i}^{+} \lambda(t)\right]\left.\right|^{2} d t,
$$

where

$$
\lambda(t)=\frac{d}{d t}\left(D\left(t, \psi_{t-t_{1}}\right)\right)-f_{i}\left(t, x_{t-t_{1}}, u(t)\right)
$$

is integrable. Consider the function $k(t)=B_{i}^{+}(t) \lambda(t)$, which is measurable in $t$ and is $L_{2}$. Therefore there is a sequence $\left\{k_{n}(t)\right\}$ of continuous functions such that

$$
\int_{t_{1}-h}^{t_{1}}\left|k(t)-k_{n}(t)\right|^{2} d t \rightarrow 0 \quad \text { as } n \rightarrow \infty
$$

Hence

$$
\begin{aligned}
& \left(\int_{t_{1}-h}^{t_{1}}|k(t+s)-k(t)|^{2} d t\right)^{\frac{1}{2}} \\
& \leq\left(\int_{t_{1}-h}^{t_{1}}\left|k(t+s)-k_{n}(t+s)\right|^{2} d t\right)^{\frac{1}{2}}+\left(\int_{t_{1}-h}^{t_{1}}\left|k_{n}(t+s)-k_{n}(t)\right|^{2} d t\right)^{\frac{1}{2}} \\
& +\left(\int_{t_{1}-h}^{t_{1}}\left|k_{n}(t)-k(t)\right|^{2} d t\right)^{\frac{1}{2}} .
\end{aligned}
$$

The last and first integrals on the right hand side of the inequality can be made arbitrarily less than $\epsilon>0$ by selecting $n$ very large. The second integral can be made 
less than $\epsilon$ if $s$ is selected small enough. This proves that

$$
\int_{t_{1}-h}^{t_{1}}\left|B_{i}^{+}(t+s) \lambda(t+s)-B_{i}^{+}(t) \lambda(t)\right|^{2} d t \rightarrow 0 \quad \text { as } s \rightarrow 0 .
$$

Therefore,

$$
\int_{t_{1}-h}^{t_{1}}|T(\zeta, u)(t+s)-T(\zeta, u)(t)|^{2} d t \rightarrow 0 \quad \text { as } s \rightarrow 0 .
$$

We now verify continuity. Note that $u \rightarrow x(\cdot, u)$ is continuous. Also $t \rightarrow B(t)$, $(t, \phi, u) \rightarrow f_{i}(t, \phi, u)$ are continuous. Let $(u),(w) \in L_{2}$ and

$$
(v(t))=T(u), \quad\left(v^{\prime}(t)\right)=T(w) .
$$

Then

$$
\begin{aligned}
\left|v(t)-v^{\prime}(t)\right| & =\left|B_{i}^{+}(t)\left(\left(\zeta^{u}-\zeta^{w}\right)+\left(f_{i}\left(t, x_{t-t_{1}}^{w_{i}}, w(t)\right)-f_{i}\left(t, x_{t-t_{1}}^{u}, u(t)\right)\right)\right)\right| \\
& =\left\|B_{i}^{+}(t)\right\|\left(\left|\zeta^{u^{i}}-\zeta^{w^{i}}\right|+\left|f_{i}\left(t, x_{t-t_{1}}^{u^{i}}, u^{i}(t)\right)-f_{i}\left(t, x_{t-t_{1}}^{w_{i}}, w(t)\right)\right|\right)
\end{aligned}
$$

Because $u^{i} \rightarrow f\left(t, x_{\mathrm{f}}^{u^{i}}, u^{i}(t)\right)$ is continuous, given any $\epsilon>0$, there is an $\eta>0$ such that if $|u(t)-w(t)|<\eta$ then $\left|f_{i}\left(t, x_{t}^{i u}, u^{i}(t)\right)-f_{i}\left(t, x_{t}^{w^{i}}, w^{i}(t)\right)\right|<\epsilon$ for all $t \in\left[\sigma, t_{1}\right]$. Divide $\left[\sigma, t_{1}\right]$ into two sets $e_{1}$ and $e_{2}$; and put the points at which $\left|u^{i}(t)-w^{i}(t)\right|<\eta$ to be $e_{1}$ and the remainder $e_{2}$. If we write $\left\|u^{i}-w^{i}\right\|_{2}=\gamma$, then

$$
\gamma^{2}=\int_{\sigma}^{t_{1}}\left|u^{i}(t)-w^{i}(t)\right|^{2} d t \geq \int_{e^{2}}\left|u^{i}(t)-w^{i}(t)\right|^{2} d t \geq \eta^{2} \operatorname{mes} e_{2},
$$

so that

$$
\operatorname{mes} e_{2} \leq \gamma^{2} / \eta^{2}
$$

Consider

$$
I=\int_{\sigma}^{t_{1}}\left|f_{i}\left(t, x_{t-t_{1}}^{u^{i}}, u^{i}(t)\right)-f_{i}\left(t, x_{t}^{w}, w(t)\right)\right|^{2} d t
$$

Obviously

$$
\begin{aligned}
I & =\int_{e_{1}}+\int_{e_{2}}\left|f\left(t, x_{t-t_{1}}^{u^{i}}, u^{i}(t)\right)-f_{i}\left(t, x_{t-t_{1}}^{w_{i}}, w(t)\right)\right|^{2} d t \\
& \leq \epsilon^{2} \operatorname{mes} e_{1}+\frac{4 \gamma^{2}}{\eta^{2}}\{\sup f(\cdot)\}^{2} \\
& \leq \epsilon^{2} \operatorname{mes} e_{1}+\frac{4 \gamma}{\eta^{2}} R^{2}
\end{aligned}
$$


for some $R_{1}$. Because $u \rightarrow \frac{d}{d t} D\left(t, x_{t}\right)$ is continuous, given $\epsilon>0$, there exists an $\eta_{2}>0$ such that if $|u(t)-w(t)|<\eta_{2}$ then $\left|\frac{d}{d t} D\left(t, \psi_{t-t_{1}}^{(u)}\right)-\frac{d}{d t} D\left(t, \psi_{t-t_{1}}^{(w)}\right)\right|<\epsilon$ for all $t \in\left[\sigma, t_{1}\right]$. Consider $e_{1}, e_{2}, \gamma$, as defined above, and

$$
J=\int_{\sigma}^{t_{1}}\left|\frac{d}{d t} D\left(t, \psi_{t-t_{1}}^{(u)}\right)-\frac{d}{d t} D\left(t, \psi_{t-t_{1}}^{(w)}\right)\right|^{2} d t .
$$

Clearly

$$
\begin{aligned}
J & =\int_{e_{1}}+\int_{e_{2}}\left|\frac{d}{d t} D\left(t, \psi_{t-t_{1}}^{(u)}\right)-\frac{d}{d t} D\left(t, \psi_{t-t_{1}}^{(w)}\right)\right| d t \\
& \leq \epsilon^{2} \text { mes } e_{1}+\frac{4 \gamma^{2}}{\eta^{2}}\{\sup \{D(t, \cdot)\}\}^{2} \\
& \leq \epsilon^{2} \operatorname{mes} e_{1}+\frac{4 \gamma^{2}}{\eta^{2}} R_{2}
\end{aligned}
$$

for some $R_{2}$. We now insert these estimates of $I$ and $J$ in (3.10). We deduce that if $|u-w|<\eta$, then $\left|\left(v(t)-v^{\prime}(t)\right)\right|^{2} \leq\left\|B_{i}^{+}\right\|\left|\zeta^{u_{i}}-\zeta^{w_{i}}\right|+\beta^{+2}\left(\epsilon^{2}+\epsilon^{2}\right)$. Thus

$$
\begin{aligned}
\left\|\left(v-v^{\prime}\right)\right\|^{2} & =\int_{t_{1}-h}^{t_{1}}\left|\left(v(t)-v^{\prime}(t)\right)\right|^{2} d t \\
& \leq+\beta^{+}\left(2 \epsilon^{2} h+\frac{4 \gamma^{2}}{\eta^{2}} R_{2}+\frac{4 \gamma^{2}}{\eta^{2}} R_{1}^{2}\right) .
\end{aligned}
$$

Because $\gamma^{2}=\|u-w\|^{2}$, the left hand side of this inequality can be made as small as possible if $u$ and $w$ are sufficiently close. This proves that $T$ is a continuous map. As claimed $T: A \rightarrow A$ is a continuous mapping of a compact convex subset of $L_{2}$ into itself. By Schauder's fixed point theorem [25, page 645], $T$ has a fixed point. With $u(3.8)$ is satisfied since $x(t)=\psi\left(t-t_{1}\right)$ on $\left[t_{1}-h, t_{1}\right]$, and

$$
f\left(t, x_{t}{ }^{i}, u(t)\right)+B(t) B^{+}(t)\left(\frac{d}{d t} D\left(t, \psi_{t-t_{1}}\right)-f\left(t, x_{t}, u(t)\right)\right)=\frac{d}{d t} D\left(t, \psi_{t-t_{1}}\right) .
$$

The history of the growth condition (iv) of Theorem 3.1 is outlined in the recent paper, [19, pages 46-51]. Inspired by these ideas we have the following corollaries.

COROLLARY 3.1. In the system in (3.1) assume

(i) condition (i)-(iii) of Theorem 3.1;

(ii)

$$
\lim _{\|(\phi, u)\| \rightarrow \infty}\left|f_{i}(t, \phi, u)\right| /\|(\phi, u)\|=0
$$

uniformly in $t\left(t \in\left[\sigma, t_{1}\right]\right)$.

Then (3.1) is controllable on $\left[\sigma, t_{1}\right] \equiv I$ with $t_{1}>\sigma+h$. 
REMARK. (3.11) is used in [16] and generalizes [29].

PROOF. Let

$$
F_{i}(\phi, u)=\sup \left\{\left|f_{i}(t, \phi, u)\right|: t \in I\right\} .
$$

Then

$$
\lim _{r \rightarrow \infty}\left(r-\sum_{j=1}^{q} c_{i} \sup \left\{F_{i j}\left(\phi, u^{i}\right):\left|\left(\phi, u^{i}\right)\right| \leq r\right\}\right)=+\infty
$$

if

$$
\liminf _{r \rightarrow \infty}\left(\frac{1}{r}\right) \sup \left\{F_{i}(\phi, u):|(\phi, u)| \leq r\right\}<\frac{1}{c_{1}} .
$$

But condition (3.11) implies (3.13) by a modification of an argument of Do [19, page 47]. The required modification is the proof that if the corresponding sequence $\left\{\left(\phi_{j}, u_{j}\right)\right\}$ is bounded we can assume it compact (see the definition of the set $A=$ $A_{1} \times A_{2}$ ). Therefore (3.12) is valid and Theorem 3.1 can be concluded.

Recall that $f(t, \phi, u)$ is said to be locally bounded in $u$ if for any $M>0$, there is an $L>0$ such that $\|f(t, \phi, u)\| \leq L$ for all $(t, \phi) \in E \times C$ and for all $\|u\| \leq M$. The next corollary is valid.

COROLlary 3.2. For the system (3.1) assume conditions (i)-(iii) of Theorem 3.1. If $f_{i}: E \times C \times E^{m}$ is locally bounded in $u$ and

$$
\lim _{\|u\| \rightarrow \infty}\|f(t, \phi, u)\| /\|u\|=0
$$

uniformly in $(t, \phi) \in E \times C$, then (3.1) is controllable on $\left[\sigma, t_{1}\right], t_{1}>\sigma+h$.

PROOF. Let $F_{i}(\phi, u)=\sup \left\{\| f_{i}(t, \phi, u): t \in I\right\}$. Then

$$
\left\|f_{i}(t, \phi, u)\right\| \leq F_{i}(\phi, u) \quad \forall(t, \phi, u) \in I \times C \times E^{m} .
$$

Because of (3.14) the following is valid:

$$
\lim _{r \rightarrow \infty}\left(\frac{1}{r}\right) \sup \left\{F_{i}(\phi, u):\|(\phi, u)\| \leq r\right\}=0 .
$$

As a consequence (3.13) holds, and the result follows.

Proof OF ThEOREM 3.2. The proof is similar to that of Theorem 3.1. The integral equation of (3.2) corresponding to (3.4) is

$$
\begin{aligned}
x^{i}(t)= & D_{i}\left(\sigma, \phi^{i}\right)+g_{i}\left(t, x_{t}{ }^{i}\right)+\int_{\sigma}^{t} f_{i}\left(s, x_{s}{ }^{i}, u^{i}(s)\right) d s \\
& +\int_{\sigma}^{t} K_{i}\left(s, x_{s}, v^{i}(s)\right) d s+\int_{\sigma}^{t} B_{i}(s) u^{i}(s) d s, \quad t \geq \sigma .
\end{aligned}
$$


The control function is defined by

$$
\begin{gathered}
u^{i}(t)=B_{i}^{*}(t) H_{i}^{-1}\left(t_{1}-\sigma\right)\left(x_{1}^{i}-\bar{\phi}^{i}\left(t_{1}-\sigma\right)+g_{i}(\sigma, \phi)-g_{i}\left(t_{1}, \bar{\phi}_{t_{1}-\sigma}^{i}+z_{t_{1}-\sigma}^{i}\right)\right. \\
\left.-\int_{\sigma}^{t_{1}-\sigma} f_{i}\left(s+\sigma, \bar{\phi}_{s}^{i}+z_{s}^{i}, u^{i}(s+\sigma)\right)+K_{i}\left(s+\sigma, \bar{\phi}_{s}^{i}+z_{s}^{i}, v^{i}(s+\sigma)\right) d s\right) .
\end{gathered}
$$

This control steers $\phi^{i}$ to $x_{1}^{i}$ in time $t_{1}$.

The additional term $\int_{\sigma}^{t} K_{i}\left(s, x_{s}, v^{i}(s)\right) d s$ is taken care of in the various estimates by using condition (ii), and noting that $\beta_{i}<\alpha_{i}$.

Just as in the proof of Theorem 3.1, under the conditions of Theorem 3.2, system (3.2) is Euclidean controllable. The corresponding $u^{i}$ which steers $\phi^{i}$ to $x_{1}{ }^{i}$ in time $t_{1}$ is given by (3.15). This is comparable to (3.6), the difference being the "Interconnection integral" $-\int_{\sigma}^{t_{1}-\sigma} K_{i}\left(s+\sigma, \bar{\phi}_{s}^{i}+z_{s}{ }^{i}, v^{i}(s+\sigma)\right) d s$. The operators $T$ and $S$ are defined as in the proof of Theorem 3.1 with the modification that

$$
S\left(z^{i}, u^{i}\right)(t)=(h(t), \underline{v}(t)) \quad \text { if } t \in[0, t]
$$

where

$$
\begin{aligned}
& h(t)= \int_{0}^{t} f_{i}\left(s+\sigma, \bar{\phi}_{s}^{i}+z_{s}^{i}, u^{i}(s+\sigma)\right) d s \\
& \quad+\int_{\sigma}^{t} B_{i}(s+\sigma) u^{i}(s+\sigma) d s+\int_{0}^{t} K_{i}\left(s+\sigma, \bar{\phi}_{s}^{i}+z_{s}^{i}, v^{i}(s+\sigma)\right) d s \\
& \underline{v}(t)=-B_{i}^{*}(t) H_{i}^{-1}\left(t_{1}-\sigma\right)\left(x_{1}^{i}-\bar{\phi}^{i}\left(t_{1}-\sigma\right)+g_{i}(\sigma \phi)-g_{i}\left(t_{1} \bar{\phi}_{t_{1}-\sigma}^{i}+z_{t_{1}-\sigma}^{i}\right)\right) \\
&-\int_{0}^{t_{1}-\sigma}\left(f_{i}\left(s+\sigma, \bar{\phi}_{s}^{i}+z_{s}^{i}, u^{i}(s+\sigma)\right)+K_{i}\left(s+\sigma, \bar{\phi}_{s}^{i}+z_{s}^{i}, v^{i}(s+\sigma)\right)\right) d s .
\end{aligned}
$$

Just as before, we prove that the operator $T+S$ defined by

$$
(T+S)\left(z^{i}, u^{i}\right)(t)=(y(t)+h(t), w(t)+v(t))
$$

has a fixed point:

$$
(T+S)\left(z^{i}, u^{i}\right)(t)=\left(z^{i}(t), u^{i}(t)\right),
$$

so that (3.2) is Euclidean controllable. We proceed as before to prove this fixed point. Suppose

$$
F_{i j}(r)=\sup \left\{F_{i j}(\phi, u):\|(\phi, u)\| \leq r\right\},
$$

so that by the growth condition there is some $r_{0}$ such that

$$
\sum_{j=1}^{q} c_{i} F_{i j}\left(r_{0}\right)+d \leq r_{0}
$$


and

$$
K_{i j}(r)=\sup \left\{K_{i j}\left(\phi^{i}, u^{i}\right):\left\|\left(\phi, u^{i}\right)\right\| \leq r\right\}
$$

so that

$$
\sum_{j=1}^{q} c_{i} K_{i j}\left(r_{0}\right)+d \leq r_{0} .
$$

We use Lemma 1.2 of Hale [23] to estimate that

$$
|h(t)| \leq \sum_{j=1}^{q}\left\|\alpha_{j}\right\| F_{i j}\left(r_{0}\right)+N_{v q}+\sum_{j=1}^{q}\left\|\beta_{j}\right\| F_{i j}\left(r_{0}\right),
$$

where $\left\|\alpha_{j}\right\|=\int_{0}^{t_{1}}\left|\alpha_{j}(s+\sigma)\right| d s,\left\|\beta_{j}\right\|=\int_{0}^{t_{1}}\left|\beta_{j}(s+\sigma)\right| d s$. Thus

$$
|h(t)| \leq \sum_{j=1}^{q}\left\|\alpha_{j}\right\|\left(F_{i j}\left(r_{0}\right)+F_{i j}\left(r_{0}\right)\right)+N_{v q}
$$

since $\beta_{j}<\alpha_{j}$ by condition (ii). This and the previous estimates yield

$$
|y(t)|+|h(t)| \leq d_{1}+\sum_{j=1}^{q} 2\left\|\alpha_{j}\right\| F_{i j}\left(r_{0}\right) \leq r_{0},
$$

where $d_{1}$ is as before and $c_{1}=\max \left\{2\left\|\alpha_{j}\right\|,\left\|\beta^{*} H^{-1}\right\|\left\|\alpha_{j}\right\|\right\}$. In the estimate for $\underline{v}(t)$ we replace $\left\|\alpha_{j}\right\|$ by $2\left\|\alpha_{j}\right\|$. Thus $T+S: A \rightarrow A$. The previous argument shows that $S: A \rightarrow S$ is continuous and compact. In the earlier argument replace $M$ by $M=M_{1}+M_{2}$, where

$$
\begin{aligned}
& M_{1}=\max _{s \in\left[0, t_{1}\right]}\left|f_{i}\left(s \mid \sigma, \bar{\phi}_{s}^{i}+t_{s}^{i}, u^{i}(s+\sigma)\right)\right|, \\
& M_{2}=\max _{s \in\left[0, t_{1}\right]}\left|K_{i}\left(s \mid \sigma, \bar{\phi}_{s}^{i}+z_{s_{1}}^{i}, v^{i}(s+\sigma)\right)\right| .
\end{aligned}
$$

The argument that $T$ is a contraction is unchanged. Lemma 1.1 of [10] asserts that $T+S$ has a fixed point, so that (3.2) is Euclidean controllable on $\left[\sigma, t_{1}\right]$. Because $B(t)$ is also Euclidean controllable on $\left[\sigma, t_{1}-h\right]$, given $\phi^{i}, \psi^{i} \in W_{2}^{(1)}\left([-h, 0], E^{n_{i}}\right)$, there is a $u \in L_{2}\left(\left[\sigma, t_{1}-h\right], E^{m_{i}}\right)$ such that $x_{\sigma}^{i}=\phi$, and $x^{i}\left(t_{1}-h, \sigma, \phi^{i}, u\right)=\psi^{i}(-h)$. This control $u$ and the solution $x^{i}\left(\cdot, \sigma, \phi_{1}^{i}, u\right)$ are extended on the interval $\left[\sigma, t_{1}\right], t_{1}>\sigma+h$ so that

$$
\frac{d}{d t} D_{i}\left(t, x_{t}{ }^{i}\right)=f_{i}\left(t, x_{i}{ }^{i}, u(t)\right)+K_{i}\left(t, x_{t}{ }^{i}, v(t)\right)+B_{i}(t) u(t)
$$

on $\left[t_{1}-h, t_{1}\right]$, where

$$
x(t)=\psi\left(t-t_{1}\right), \quad t_{1}-h \leq t \leq t_{1} .
$$


Define a control

$$
u(t)=B_{i}^{+}(t)\left(\frac{d}{d t} D_{i}\left(t, x_{t}^{i}\right)-f_{i}\left(t, x_{t}^{i}, u(t)\right)-K_{i}\left(t, x_{t}^{i}, v(t)\right)\right)
$$

for $t_{1}-h \leq t \leq t_{1}$, where $B_{i}{ }^{+}$is the generalized inverse of $B_{i}$. It is easy to prove that with this $u, x$ satisfies (3.16). To prove the existence of $u$ in (3.17) we modify the earlier proof when $K_{i} \equiv 0$. To account for interconnection $K_{i}$ there is an additional term $\sum_{j=1}^{q} \beta_{j}(t) F_{i j}\left(x_{t}{ }^{i}, u^{i}(t)\right)$ which yields

$$
\begin{aligned}
|v(t)| & \leq \beta^{+}\left(\left|\dot{D}\left(t, \psi_{t-t_{1}}\right)\right|+\sum_{j=1}^{q} 2\left|\alpha_{j}(t)\right| F_{i j}\left(r_{0}\right)\right) \\
& \leq \frac{1}{3 k}\left(d_{2}+\sum_{j=1}^{q} c_{j} F_{i j}\left(r_{0}\right)\right) .
\end{aligned}
$$

With minor modification the rest of the proof is complete.

REMARK. It may be said that $\beta_{i}$ is a measure of the action of the whole system $S$ on its $i$ th interconnected subsystem, while $\alpha_{i}$ is a measure of the subsystem's internal power. To ensure controllability, $\alpha_{i}>\beta_{i}$. Broad policy implications of this are pursued in [9].

\section{Acknowledgements}

This research is partially supported by the National Science Foundation under Grant NSF DMS 9020917.

The author is grateful to the referee whose criticism led to the inclusion of Remark 3.3 and the removal of some obscurities by including some details in the proof of Theorem 3.2.

\section{References}

[1] R. G. D. Allen, Mathematical economics (Macmillan \& Co., Ltd., London, 1973).

[2] K. J. Arrow, Production and capital, Collected papers of Kenneth J. Arrow (The Belenap Press of Harvard University Press, Cambridge, Massachusetts, 1985).

[3] K. Balchandran and J. P. Dauer, "Relative controllability of perturbations of nonlinear systems", J. Optim. Theory Appl. 63 (1989) 51-56.

[4] H. T. Banks, M. Q. Jacobs and C. E. Langenhop, "Characterization of the controlled states in $W_{2}^{(1)}$ of linear hereditary systems", SIAM J. Control 13 (1975) 611-649.

[5] Z. Bartosiewicz, "Closedness of the attainable set of the linear neutral control system", Control and Cybernetics 8 (1979) 179-189.

[6] S. L. Campbell and C. D. Meyer, Generalized inverses of linear transformations (Pitman, London, 1979). 
[7] E. N. Chukwu, "Some controllability questions of linear and nonlinear neutral functional differential equations in $W_{2}^{(1)}$," preprint.

[8] E. N. Chukwu, "Controllability of delay systems with restrained controls", J. Optim. Theory Appl. 29 (1979).

[9] E. N. Chukwu, "Uniform asymptotic stability of large scale systems of neutral type", in IEEE Proc. 8th Southeastern Symp. Systems Theory, (Computer Society Press, Knoxville, TN, April 7-8 1986).

[10] E. N. Chukwu, "On the Euclidean controllability of a neutral system with nonlinear base", Nonlinear analysis, theory, methods and applications 11 (1987) 115-123.

[11] E. N. Chukwu, "The time optimal control theory of linear differential equations of neutral type", Comput. Math. Appl. 16 (1988) 851-866.

[12] E. N. Chukwu, "Global economic growth: will the center hold?", in Ordinary and delay differential equations (eds. J. Wiener and J. K. Hale), (Longman, New York, 1992) 19-23.

[13] E. N. Chukwu, "Mathematical controllability theory of the growth of wealth of nations", in 1st world congress of nonlinear analysis, Tampa, Florida (ed. V. Lakshmikantham), 1992).

[14] E. N. Chukwu, Stability and time-optimal control of hereditary systems (Academic Press, New York, 1992).

[15] E. N. Chukwu and H. C. Simpson, "Perturbations of nonlinear systems of neutral type", J. Differential Equations 82 (1989) 28-59.

[16] J. P. Dauer, "Nonlinear perturbations of quasilinear control systems", J. Math. Anal. Appl. 54 (1976) 717-725.

[17] K. Deimling, Nonlinear functional analysis (Springer-Verlag, New York, 1985).

[18] J. Dieudonne, Foundations of modern analysis (Academic Press, New York, 1960).

[19] V. N. Do, "Controllability of semilinear systems", J. Optim. Theory Appl. 65 (1990) 41-52.

[20] O. Hájek, Pursuit games (Academic Press, 1975).

[21] J. Hale, "Forward and backward continuation of neutral functional differential equations", $J$. Differential Equations 9 (1971) 168-181.

[22] J. Hale, Theory of functional differential equations (Springer-Verlag, New York, 1977).

[23] J. Hale and M. A. Cruz, "Existence, uniqueness and continuous dependence for hereditary systems", Ann. Mat. Pura Appl. (4) 85 (1970) 63-82.

[24] M. Kalecki, “A macrodynamic theory of business cycles", Econometrica 3 (1935) 327-244.

[25] L. V. Kantorovich and G. P. Akilov, Functional analysis in normed spaces (Macmillan, New York, 1964).

[26] G. E. Ladas and V. Lakshmikantham, Differential equations in abstract spaces (Academic Press, New York, 1972).

[27] M. McElroy, The macroeconomy; private actions; public choices and aggregate outcome (Macmillan, New York, to appear).

[28] A. N. Michel and R. K. Miller, Qualitative analysis of large scale dynamical systems (Academic Press, New York, 1977).

[29] K. B. Mirza and B. F. Womack, "On the controllability of nonlinear time-delay systems", IEEE Trans. Automat. Control (December 1972) 812-814.

[30] A. W. Mullinex, The business cycle after Keynes: A contemporary analysis (Barnes and Noble, New Jersey, 1984).

[31] Jeffrey Sachs and Felipe Larrain, Macroeconomics in the global economy (Prentice Hall, 1993).

[32] D. Salamon, Control and observations of neutral systems (Pitman, Boston, 1984).

[33] M. Slemrod, "The flip-flop circuit as a neutral equation", in Delay and functional differential equations and their applications, (Academic Press, 1972). 